Nadira A Hatim

BDS, MSc (Assist Prof)

Isam K Al-Khayat

BSc, PhD (Assist Prof)

Mohammed A Abdullah

BDS, MSc (Assist Lect)

\section{Modification of Gypsum Products (Part III): Practical Application of Modified Gypsum Products}

\author{
Department of Prosthetic Dentistry \\ College of Dentistry, University of Mosul \\ Department of Dental Basic Sciences \\ College of Dentistry, University of Mosul \\ Department of Prosthetic Dentistry \\ College of Dentistry, University of Mosul
}

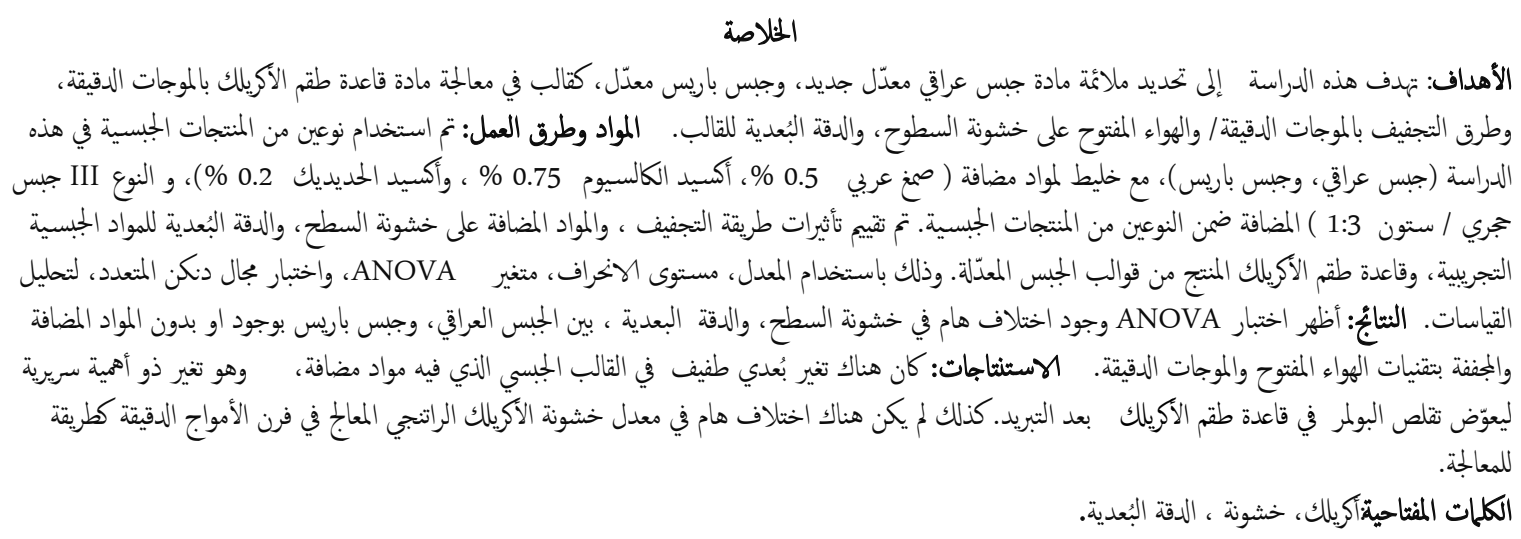

ABSTRACT

Aims: To determine the suitability of new modified Iraqi plaster and modified Plaster of Paris as a cast in microwave curing of acrylic denture base material, and microwave and open air drying methods on the surface roughness and dimensional accuracy of the cast. Materials and methods: Two types of gypsum products were used in this study \{(Iraqi plaster, Plaster of Paris) with the combined additives (Gum Arabic $0.5 \%$, calcium oxide $0.75 \%$, and ferric oxide $0.2 \%$ ), and Type III stone Plaster/Stone 3:1\} that incorporated within the two gypsum products. The effects of drying method and combined additives on the surface roughness and dimensional accuracy of the experimental gypsum products, and acrylic denture base produced from the modified gypsum casts have been evaluated. Mean, standard deviation, variance (ANOVA), and Duncan's multiple range tests were used to analyze the measurements. Results: ANOVA test showed that there was a significant difference in the surface roughness and dimensional accuracy between Iraqi plaster and plaster of Paris with or without additives dried in open air and microwave techniques. Conclusion: There was slight dimensional change in the gypsum cast with additives of clinical importance to compensate the polymer shrinkage of the acrylic denture base after cooling. There was no significant difference in the average roughness of acrylic resin cured by microwave oven as a curing method.

Keywords: acrylic, roughness, dimensional accuracy.

" Hatim NA, Al-Khayat IK, Abdullah MA. Modification of Gypsum Products (Part III): Practical Application of Modified Gypsum Products. Al-Rafidain Dent J. 2010; 10(1):17-24.

Received: $5 / 2 / 2008 \quad$ Sent to Referees: $20 / 2 / 2008$

Accepted for Publication: 21/4/2008

\section{INTRODUCTION}

The size of indentation of prosthesis constructed against gypsum cast is of impor- tance, because approximately $1 \mu \mathrm{m}$ accommodate cocci and approximately $5 \mu \mathrm{m}$ to accommodate yeasts, while the maximum 
roughness that indicate peaks may play a part in causing the mechanical trauma of tissue under the prosthesis ${ }^{(1)}$. Accurate working models for the fabrication of accurate restoration are of great importance, because that even minimal dimensional change of the master models in relation to the preparation angle may lead to the significant vertical discrepancies ${ }^{(2)}$. Error in the impression may be a cause of the dentist himself, by the impression materials, or by the impression techniques ${ }^{(3,4)}$. Once the gypsum material has set, there is little or no dimensional change $e^{(5)}$. Accuracy of the gypsum cast is affected by the dimensional change associated with impression material during setting ${ }^{(6)}$.

The surface of an acrylic denture should be smooth, this has the effect of removing surface cracks, which would otherwise act as a stress- raisers, and yields a smooth surface unsuitable for the retention of bacteria and plaque ${ }^{(7)}$. So, the aims of this study were to determine the suitability of new modified Iraqi plaster and modified Plaster of Paris as a cast in microwave curing of acrylic denture base material, microwave and open air drying methods on the surface roughness and dimensional accuracy of the cast.

\section{MATERIALS AND METHODS}

The Materials used in this study were \{ Iraqi Plaster(Al-Ahliya Co. for gypsum industries Ltd/ Baghdad), Plaster of Paris (British gypsum Newark U.K 41593/106)\}, with the combined additives (gum Arabic $0.5 \%$, calcium oxide $0.75 \%$, and ferric oxide $0.2 \%$, and Type III stone Plaster/Stone $3: 1\}^{(8)}$

- Surface Roughness Measurement of the Modified Gypsum Products Cast: The gypsum products samples were prepared by mixing the powder (with or without additives) with a distilled water, mechanically spatulated under vacuum for 60 seconds, and divided into two groups. First group was without and with additives. The second group was dried by two methods:

1. Open Air: The samples were prepared and left for 24 hours from the starting point of mixing, and then measured.

2. Microwave Drying: The samples were prepared and left for 2 hours from the start- ing of mixing, and then dried by microwave according to the drying cycle (800 watts for 10 minutes) and then measured.

Surface roughness samples were prepared with dimensions $(4 \times 4 \times 0.5 \mathrm{~cm}){ }^{(9)}$, followed by two glass slabs put on the top and bottom of the moulds to get a smooth surface and a constant load about $500 \mathrm{gm}$ was placed on the upper slab. The samples were left for setting for one hour at ambient temperature $23 \pm 2{ }^{\circ} \mathrm{C}$ and relative humidity of $50 \pm 10 \%$ then kept under the same condition to be tested with Profilometer ${ }^{(10)}$. The number of samples prepared is forty.

- Surface Roughness Measurement of Acrylic Resin Denture Base Produced from a Modified Gypsum Products: Modeling wax (Major Prodotti, Italy) of $2.5 \mathrm{~mm}$. thickness of the denture base (ADA specification No.12, 1975) was used. The wax was sealed to the gypsum sample, flasking was done by ordinary procedure using a fiber reinforced plastic flask ${ }^{(11)}$, and placed into the microwave for wax elimination for one minute at a medium power (450 watts). Then the flask was opened and flushed both parts thoroughly with a boiling water and detergent. A fine brush (№. 0) was used to spread the separating medium on the exposed surfaces of a warm clean gypsum moulds. The separator was permitted to dry. Polymer and monomer of heat cured poly methyl methacrylate proportioned were mixed according to the manufacture's instructions. The flask was packed with the acrylic resin material, and placed in the microwave for curing for 30 minutes at low setting (80 watts), 15 minutes preside followed by 1.5 minutes at the medium setting (450 watts) $)^{(12)}$, and then the flask was left a side for slow bench cooling before opening. Surface roughness measurement of acrylic resin was followed as for the gypsum product sample using the Profilometer machine. The number of samples prepared is forty.

- Dimensional Accuracy Measurement of Maxillary Gypsum Cast: A maxillary metal arch form (model 41-51, Co-Lumbia Dentoform Corp, Long Island City, N.Y.) was used as the master model. Three stainless steel rods were fixed on the cast to produce a point reference mark. The machined reference marks were then attached to the master arch form with cyanoacrylate (Zapit, Dental 
Ventures of America, Inc. Calif) to provide points for measurement of the reference marks: 1 in the middle at the area of the inci-

sive papilla, 2, and 3 in the area of the right and left second premolars respectively ${ }^{(13)}$ which was located as follows (Figure 1).

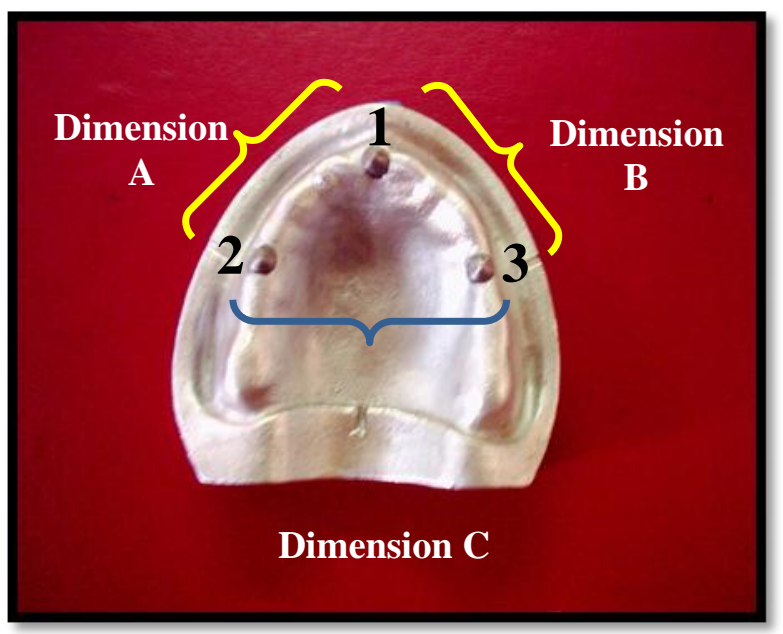

Figure (1): Maxillary metal arch with references marks.

A relief template was made for the fabrication of the auto polymerizing acrylic resin perforated special tray by the adaptation of one thickness of modeling wax to the master model form with the reference marks by using the dental surveyor. A carbide bur shaft with a special screw was placed in the vertical arm of the dental surveyor, and at- tached to the special tray for the vertical alignment of the special tray. The horizontal alignment of special tray during taking the impression to prevent the horizontal movement was done by using three nodes of acrylic in the special tray locked in a three slots on the master model (Figures 2) with four stoppers (two in each sides).

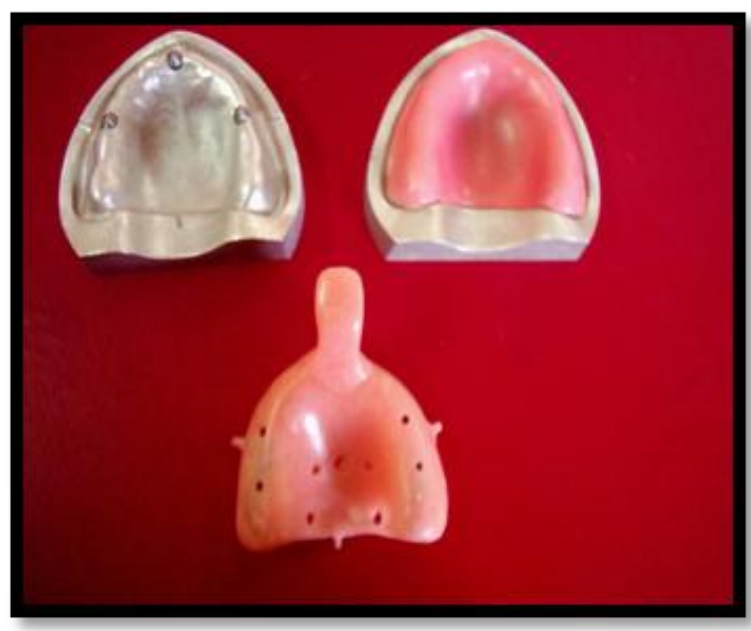

Figure (2): Construction of special tray .

This alignment procedure was used to maintain the desired impression thickness. Type I high viscosity and light body poly- vinyl siloxane impression material was used to make impressions (Figure 3). 


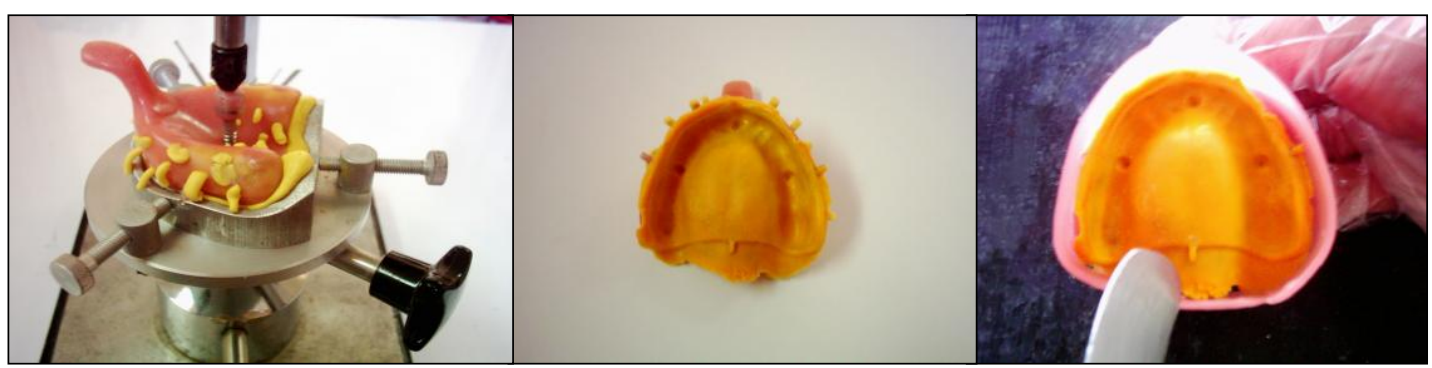

Figure (3): Impression technique and pouring procedure (Boxing technique).

Four types of the gypsum materials were used, and according to the previously determined water/ powder ratio ${ }^{(8)}$, gypsum product was mixed under a vacuum mixer for 60 seconds. The measurements for the first group were done after 2 hours from starting point of mixing in the open air, and the second left to set 2 hours from start of mixing then dried by microwave. All casts (40 samples) were measured by using a digital caliber handled on the surveyor by using special handle ${ }^{(14)}$.

Each specimen was measured in an ordered sequence, namely dimension $\mathrm{A}$, the distance between reference marks 1 and 2; dimension $\mathrm{B}$, the distance between reference marks 1 and 3; and dimension $\mathrm{C}$, the distance between reference marks 2 and 3 . The measurements were repeated three times to determine the mean for each dimension. The number of samples prepared is forty.

\section{RESULTS AND DISCUSSION}

- Surface Roughness of the Gypsum Products: The results obtained in table (1 and 2) showed that there is a significant difference $(P \geq 0.001)$ in the surface roughness between the two types of the gypsum products without additives.

Table (1) Mean, and standard deviation of the surface roughness of gypsum products with and without additives, and acrylic resin(air drying).

\begin{tabular}{cccc}
\hline Types of gypsum products & $\begin{array}{c}\text { Surface Roughness } \\
(\boldsymbol{\mu m}) \quad \text { Mean } \pm \text { SD }\end{array}$ & $\begin{array}{c}\text { Major acrylic } \\
\text { resin Mean } \pm \text { SD }\end{array}$ & N \\
\hline Iraqi plaster without additives & $1.0940 \pm 0.06914$ & $1.110 \pm 0.1208$ & 5 \\
Plaster of Paris without additives & $0.8060 \pm 0.07162$ & $1.000 \pm 0.2424$ & 5 \\
$\quad$ Iraqi plaster +Additives & $0.2980 \pm 0.07328$ & $0.6180 \pm 0.1270$ & 5 \\
Plaster of Paris +Additives & $0.7140 \pm 0.05595$ & $0.9340 \pm 0.3731$ & 5 \\
\hline
\end{tabular}

$\mathrm{SD}=$ standard deviation, $\mathrm{N}=$ number of sample.

Table ( 2 ): Analysis of variance (ANOVA) for levels of gypsum products with and without additives dried by open air on the surface roughness.

\begin{tabular}{|c|c|c|c|c|}
\hline Test & $\begin{array}{l}\text { Sum of } \\
\text { Squares }\end{array}$ & df & Mean Square & P-value \\
\hline $\begin{array}{c}\text { Surface roughness }(\mu \mathrm{m}) \text { without } \\
\text { additives }\end{array}$ & 0.912 & 3 & 0.304 & $0.001 *$ \\
\hline $\begin{array}{c}\text { Surface roughness }(\mu \mathrm{m}) \text { with addi- } \\
\text { tives }\end{array}$ & -10.089 & 8 & 0.04123 & $0.001 *$ \\
\hline
\end{tabular}

The Iraqi plaster has the highest degree of surface roughness followed by Plaster of Paris. This could be attributed to the differ- ence in the rate of the water/ powder ratio for each gypsum product. The gypsum product which has the highest surface roughness 
has the highest water/powder ratio, while the gypsum material which has the lowest surface roughness has the lowest water/ powder ratio. The water /powder ratio is critical, where improper use of gypsum products causing the excess water considered as free water (residual un reacted water) in the setting mass, and contributes to subsequent voids in the final set mass occurred between clumps of gypsum crystals ${ }^{(15,16)}$. Or this could be due to gypsum particle size, shape, and compaction between them is the main factors in determining the amount of the water/ powder ratio. The lower surface area permits the use of lower water/ powder ratio to gain a workable mass resulting in less porous and denser for the final set mass ${ }^{(17)}$.

After incorporation of the combined additives for both the Iraqi plaster and Plaster of Paris, there is a significant reduction in the degree of the surface roughness, for the Iraqi plaster (Table 3).

Table (3) Mean and standard deviation of the surface roughness of the two gypsum products without additives , microwave drying and acrylic resin.

\begin{tabular}{|c|c|c|c|}
\hline $\begin{array}{l}\text { Types of gypsum prod- } \\
\text { ucts }\end{array}$ & $\begin{array}{c}\text { Surface Roughness }(\mu \mathrm{m}) \\
\text { Mean } \pm \text { SD }\end{array}$ & $\begin{array}{c}\text { Major acrylic resin }(\mu \mathrm{m}) \\
\text { Mean } \pm \text { SD }\end{array}$ & $\mathbf{N}$ \\
\hline $\begin{array}{c}\text { Iraqi plaster without ad- } \\
\text { ditives }\end{array}$ & $1.1700 \pm 0.0578$ & $1.45 \pm 0.158$ & 5 \\
\hline $\begin{array}{c}\text { Plaster of Paris without } \\
\text { additives }\end{array}$ & $0.8520 \pm 0.07918$ & $0.966 \pm 0.087$ & 5 \\
\hline $\begin{array}{c}\text { Iraqi plaster with addi- } \\
\text { tives }\end{array}$ & $0.4080 \pm 0.0319$ & $0.9860 \pm 0.750$ & 5 \\
\hline $\begin{array}{c}\text { Plaster of Paris with ad- } \\
\text { ditives }\end{array}$ & $0.8940 \pm 0.1006$ & $1.1410 \pm 0.110$ & 5 \\
\hline
\end{tabular}

This can be explained due to reduction in the water/ powder ratio (effects of additives) and to the effect of adding type III stone at a specific ratio, because of the difference in size, shape of the crystals, and the interference. Dispersion of small crystals among large crystals affect the quantity of water necessary for mixing leading to an increase in the density, less porosity, and reduction of roughness of the set sample ${ }^{(18)}$. While, for Plaster of Paris the reduction in surface roughness may be attributed to the effect of additives. Those may fill the space between gypsum crystals and consume the excess water for slaking process of the cal- cium oxide to be converted to calcium hydroxide, after exposure to the moisture, so additives improve the density and reduce the voids in the set sample. By the use of the microwave oven as a drying method for both of Iraqi plaster and Plaster of Paris with or without additives (Table 4) showed significance difference $(\mathrm{P} \geq 0.001)$. This could be explained by the rapid escape (expulsion) of the steam water from the tested samples after exposure to radiations within the microwave that might create a micro porosity on the outer surface of the dried sample when tested by photomicrography.

Table (4): Independent sample t-test for quality of mean for the two gypsum products without and with additives, microwave drying on the surface roughness.

\begin{tabular}{ccccc}
\hline Surface Roughness & t & df & SE & $\boldsymbol{P}$-value \\
\hline Gypsum without additives & 7.250 & 8 & 0.04386 & $0.001^{*}$ \\
Gypsum with additives & -10.292 & 8 & 0.04722 & $0.001^{*}$ \\
\hline
\end{tabular}

* Significant difference . $\mathrm{P} \geq 0.001 \quad \mathrm{df}=$ degree of freedom $\quad \mathrm{SE}=$ standard error

Practically, this was noticed when the excess water covered the outer surface of the microwaved wet gypsum sample, it looks like sponge when water squeezed from it, so that it is not recommended to use the microwave oven for drying extremely wet 
casts, otherwise cracks or holes would be obtained $^{(19)}$.

Surface Roughness of a Cured Acrylic Resin: The results in table (1 and 3) showed that there is no significant difference in the average roughness of acrylic resin cured by microwave oven as a curing method. However, there is slight increase in the average roughness of each group of acrylic when compared with the average roughness of the gypsum sample used as a mould for curing the acrylic resin against it. This may be due to the effect of separating medium that may change the surface texture of the gypsum sample, which poured against smooth glass slab despite of that the separating medium applied in one direction on the warmed gyp- sum surface with two layers. This is recommended by Phillips ${ }^{(20)}$, or the increasing in the average roughness obtained due to the micro porosity which persists as a processing defect, the generation of porosity is a complex phenomenon with multi factorial origins, so the choice of a suitable microwave power and polymerization time accurately is important in order to reduce porosity to a minimum level ${ }^{(21,22)}$.

- Dimensional Accuracy of Maxillary Gypsum Cast: The results obtained in tables (5), and Figures (4\&5), demonstrate differences in the relative change that are dependent on the location of the measurement and the type of gypsum materials.

Table (5): Independent sample t-test for quality of mean for the two gypsum products Without and with additives for dimensions A, B, and C.

\begin{tabular}{ccccccc}
\hline & Product & Dimension & T & Df & SE & P-value \\
\hline \multirow{6}{*}{ without additives } & A & 0.065 & 3 & 0.021 & 0.929 \\
\multirow{3}{*}{ gypsum } & B & 0.502 & 3 & 0.167 & $0.002^{*}$ \\
& \multirow{4}{*}{ with additives } & C & 0.432 & 3 & 0.144 & 0.030 \\
& & $\mathrm{~A}$ & -0.172 & 8 & 0.097529 & 0.868 \\
& & $\mathrm{~B}$ & 5.701 & 8 & 0.037435 & $0.001^{*}$ \\
& & $\mathrm{C}$ & -0.088 & 8 & 0.11184 & 0.932 \\
\hline
\end{tabular}

A: distance between reference marks 1 and 2. B: distance between reference marks 1 and 3. C: distance between reference marks 2 and 3. * Significant difference, $\mathrm{df}=$ degree of freedom,

$\mathrm{SE}=$ standard error

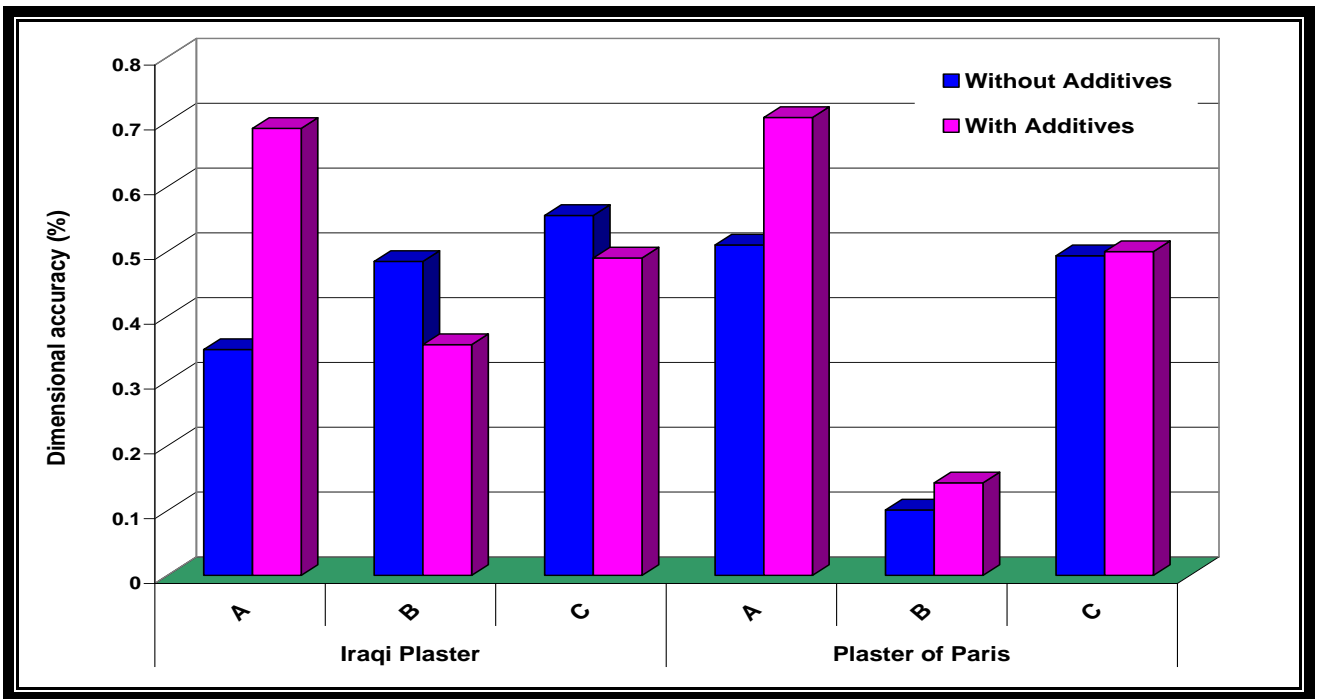

Figure (4): Means of the dimensional accuracy for gypsum products with and without additives dried by open air. 


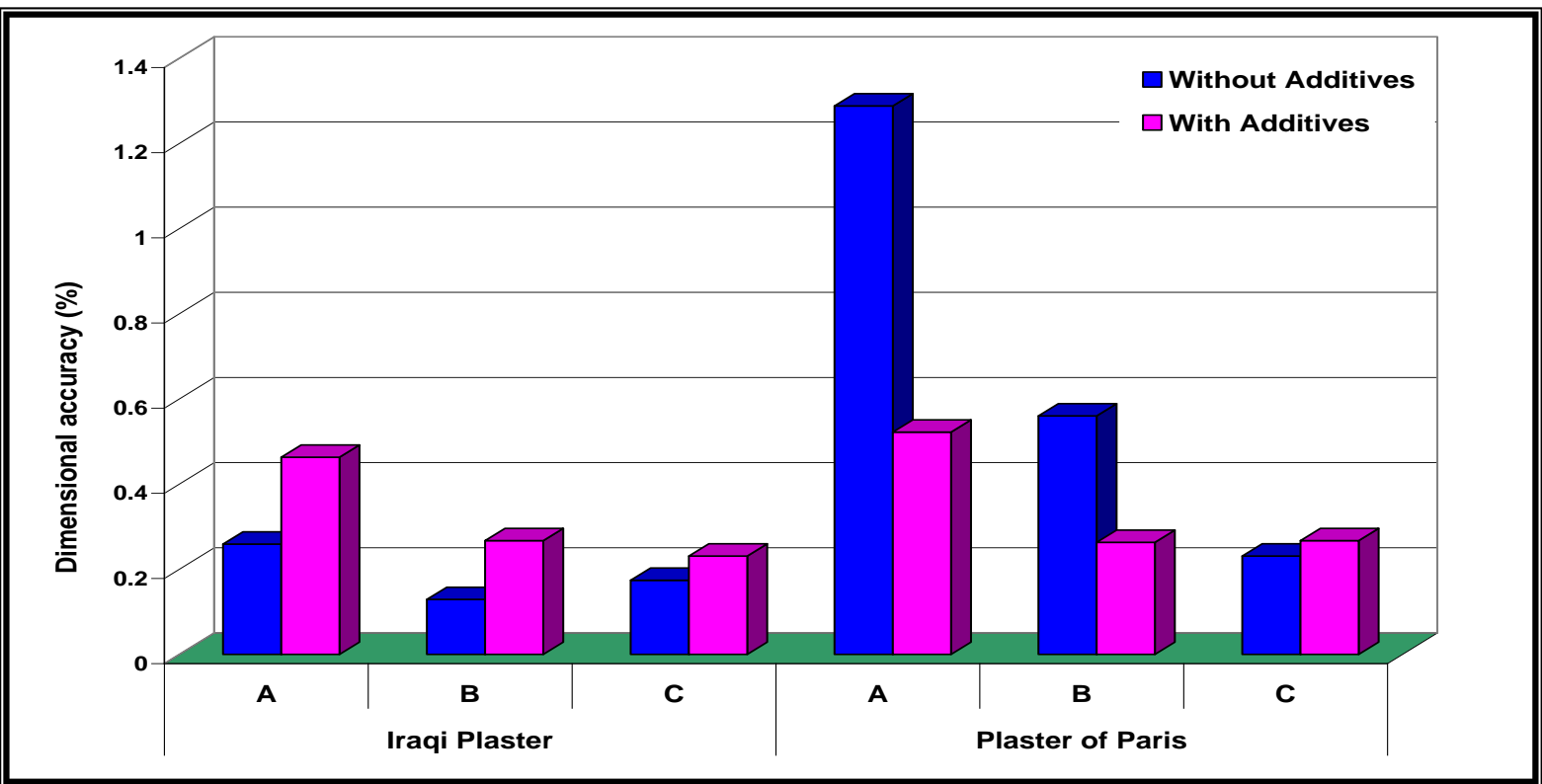

Figure (5) Means of the dimensional accuracy for gypsum products with and without additives dried by microwave.

The magnitude of the differences in the relative change in dimensions $\mathrm{A}, \mathrm{B}$, and $\mathrm{C}$ has no major problems when used clinically for construction of complete denture. The slight dimensional change in the gypsum cast is of clinical importance to compensate the polymer shrinkage of the acrylic denture base after cooling. Further investigation is required to determine the source of dimensional differences when using different kinds of gypsum materials.

\section{CONCLUSIONS}

There was slight dimensional change in the gypsum cast with additives of clinical importance to compensate the polymer shrinkage of the acrylic denture base after cooling. There was no significant difference in the average roughness of acrylic resin cured by microwave oven as a curing method.

\section{REFERENCES}

1- Veres EM, Wolfardt J, Fand Beckeer PJ. An evaluation of surface characteristic of a facial prosthetic elastomer Part II: The surface texture. J Prosthet Dent. 1990; 63(3):325331.

2- Marxkors R. Abfomfehler and deven vermeidung. Zahnarztl Welt Rdsch. 1985; 94:466-473.
3- Lim KC, Chang YH, Soh G: Effect of operator variability on void formation in impression made with an auto mixed addition silicon. Aust Dent J. 1992; 37:35-38.

4- Lee IK-Delong R, Pintado MR, Malic R. Evaluation of factors affecting the accuracy of impressions using quantitative surface analysis. Oper Dent J.1995; 20:246-252.

5- Noort RN: Introduction to dental materials. $2^{\text {nd }}$ ed. Mosby Comp. 2002. pp 205-210

6- Craig RG, O'Brien WJ, Power JM: Dental materials properties and manipulation. $6^{\text {th }}$ ed. Mosby Co. 1996.pp 242-265.

7- Ray N (1998): Dental materials Science. Mosby Co. 1998. pp38-48.

8- Hatim NA, Al-Kayat IK, Abdullah MA. Modification of gypsum products(Part I): Physical and mechanical properties of adding some additives on different types of gypsum products. Al-Rafidian Dent $J$ 2007: in press.

9- Onizuka T, Kamimura N, Kajiwara H, Nakashima A, Suenage K, Jimi T: Influence of boiling water treatment on surface roughness and surface microstructure of set gypsum (dental stone ) J Dent Mat. 1995; 14(2): 245-255.

10- Wiktorsson GC, and Feder D: Quality of stone dies produced by different impression materials. Swed Dent J.1983; 7:77-83.

11- Hasan RH: Comparison of some physical properties of acrylic denture base materials cured by water bath and microwave tech- 
nique, Al-Rafidain Dent J.2002; 3:143-147.

12- Al- Azzawi SI: Evaluation of some physical and mechanical properties of acrylic denture base materials cured by two different types of microwave irradiation. MSc Thesis, University of Baghdad 1998.

13- Chaffee NR, Bailey JH, Sherrard DJ: Dimensional accuracy of improved dental stone and epoxy resin die materials Part II: Complete arch form J Prosthet Dent.1997; 77(2):235-238.

14- Al- Mashaiky BM: Dimensional accuracy of the direct and indirect impression techniques for the endosteal implant (a comparative study) MSc Thesis, University of Mosul 2005.

15- Scrabeck JG, Fames WB, Hicks MJ: Spatulation methods and porosities in investments and impression materials $J$ Prosthet Dent. 1986; 55(3): 332-335.

16- O'Brien WJ. Dental materials and their selection $2^{\text {nd }}$ ed. Quintessence book. 2002. P.56.

17- Anusavice KJ . Phillips science of dental materials $10^{\text {th }}$ ed. WB Saunder Com. 1996.Pp 185-208.

18- Prombonas A and Vlissidis D . Compressive strength and setting temperatures of mixes with various proportion of plaster to stone. J Prosthet Dent.1994; 72(1): 95-100.

19- Luebke RJ and Chan KC . Effect of microwave oven drying on surface hardness of dental gypsum products. $J$ Prosthet Dent.1985; 54(3):431-435.

20- Phillips RW: Skinner Science of dental material $8^{\text {th }}$ ed. WB Saunders Comp.1982. pp 10-28, 63-90, 77.

21- Compagnoni MA, Barbosa DB, Desouza $\mathrm{RF}$, and Pero AC: The effect of polymerization cycles on porosity of microwaveprocessed denture base resin .J Prosthet Dent.2004; 91(3): 281-285.

22- Lai CP, Tsai MH, Chen M, Charge HS, and Tay HH: Morphology and properties of denture acrylic resins cured by microwave energy and conventional water bath .Dent Mat. 2004; 20: 133-141.

23- Chaffee NR, Bailey JH, and Sherrard DJ: Dimensional accuracy of improved dental stone and epoxy resin die materials Part II: Complete arch form. J Prosthet Dent.1997; 77(2):235-238.

24- Ishida K: Accuracy of complete dental arch impression and stone casts using a three dimensional measurements system (effect on accuracy of rubber impression materials and trays). Dentistry in Japan.1990; 27: 73-79. 